\title{
Atividades produtivas e não-produtivas no Brasil: uma análise clássico-marxiana, 2010-2015
}

Productive and non-productive activities in Brazil: a classic-Marxian analysis

\author{
Pedro Henrique Feliciano Dias Sampaio a \\ Alessandro Donadio Miebach ${ }^{b}$ \\ Henrique Morrone ${ }^{c}$
}

\begin{abstract}
Resumo: Este artigo se dedica à construção de indicadores alternativos para a contabilidade nacional brasileira sob a tradição clássico-marxiana. A partir da metodologia proposta por Shaikh e Tonak (1994), foram estimadas categorias-chave na tradição marxiana - como o capital variável, a massa de mais-valor e as taxas de exploração e lucro - utilizando as matrizes de insumo-produto para os anos 2010 e 2015 . O objetivo é avaliar a recente trajetória de expansão e declínio da economia brasileira à luz da economia política, destacando o crescimento de atividades e ocupações não-produtivas.
\end{abstract}

Palavras-chave: Economia Política; Contabilidade Social; Economia Brasileira. Classificação JEL: B51, E01, E11, P16

\begin{abstract}
This paper aims to the construction of alternative measures for Brazilian national accounting under the Classical-Marxian tradition. From the methodology proposed by Shaikh and Tonak (1994), key categories in the Marxian tradition were estimated - such as variable capital, the mass of surplus-value and the rates of exploitation and profit - using input-output matrices for the years 2010 and 2015. The main goal is to evaluate the recent path of expansion and decline of the Brazilian economy in the light of political economy, highlighting the growth of nonproductive activities and occupations.
\end{abstract}

Keywords: Political Economy; Social Accounting; Brazilian Economy.

JEL Classification: B51, E01, E11, P16

\footnotetext{
${ }^{\text {a }}$ Bacharel em Ciências Econômicas pela Faculdade de Economia da Universidade Federal da Bahia (UFBA). Mestre e Doutorando em Economia (área de concentração em Economia do Desenvolvimento) pelo PPGE/UFRGS. Pesquisador Bolsista no Núcleo de Estudos em Economia Criativa e da Cultura (NECCULT/UFRGS). Email: sampaiopedro@ outlook.com.br.

b Professor da Faculdade de Ciências Econômicas e do Programa de Pós-Graduação em Economia da Universidade Federal do Rio Grande do Sul (FCE e PPGE/UFRGS). Email: aledonadio@ gmail.com.

c Professor da Faculdade de Ciências Econômicas e do Programa de Pós-Graduação em Economia da Universidade Federal do Rio Grande do Sul (FCE e PPGE/UFRGS). Email: hmorrone@ hotmail.com.
} 


\section{Introdução}

A mensuração da riqueza das nações é um desafio histórico que se impõe à economia política. Ao longo do século XX, o System of National Accounts (SNA), elaborado pela Organização das Nações Unidas (ONU), se consolidou como padrão internacional de estimação dos agregados econômicos nacionais. Não obstante a ampla aceitação da metodologia, uma parcela crescente da literatura tem enfatizado as limitações dos indicadores econômicos convencionais para a apreensão de novas tendências do capitalismo contemporâneo.

Partindo desta premissa, o presente artigo propõe a construção de indicadores alternativos para as contas nacionais do Brasil, promovendo uma reaproximação entre a economia política e a contabilidade social. Utilizando a metodologia desenvolvida por Shaikh e Tonak (1994), é possível estimar categorias-chave da tradição marxiana para a economia brasileira, tais como o mais-valor, a taxa de exploração, a taxa de lucro, dentre outras variáveis. Esta abordagem se diferencia do modelo SNA por considerar determinadas atividades econômicas, comumente incorporadas à categoria de "produção", como formas de consumo social.

Na contabilidade social convencional, a definição de "produção", ou "fronteira de produção" na nomenclatura usual, compreende toda e qualquer atividade envolvida em transações de compra e venda no mercado ${ }^{1}$. A partir de Shaikh e Tonak (1994), o presente trabalho adota outra delimitação, fundamentada no marco teórico clássico-marxiano. Tratase da noção de atividades produtivas e não-produtivas, ou improdutivas, de acordo com sua posição no circuito do capital e capacidade de produção de mais-valor.

Esta abordagem afeta o tratamento analítico de setores dependentes da recirculação do mais-valor criado na produção, que passam a ser computados à parte nas estimativas dos agregados nacionais. Apesar de suas atividades resultarem em lucro contábil, setores como o financeiro, imobiliário, comercial, jurídico, administração pública, dentre outros, consomem valores pré-existentes sem a produção de mais-valor como contrapartida.

$\mathrm{Na}$ tradição da economia política clássica/marxiana, a expansão da esfera nãoprodutiva implica na redução do potencial de acumulação e crescimento econômico. De acordo com Marx (2013[1867]), as crescentes transferências do mais-valor criado na produção para atividades não-produtivas pode engendrar períodos de instabilidade econômica, estagnação e crises. A partir da segunda metade do século XX, Moseley (1985), Shaikh e Tonak (1994) e Paitaridis e Tsoulfidis (2012) têm constatado a expansão das

\footnotetext{
${ }^{1}$ Algumas outras atividades são incluídas através de imputações, como por exemplo, no caso de imputações de serviços de moradias aos proprietários de imóveis. Hallak e Ramos (2014) apresentam uma discussão sobre a fronteira de produção no atual sistema de contas brasileiro.
} 
atividades não-produtivas na economia global, assim como o crescimento das ocupações não produtivas no mercado de trabalho. ${ }^{2}$

Utilizando-se as matrizes insumo-produto do Instituto Brasileiro de Geografia e Estatística (IBGE), o presente artigo estima as principais categorias marxianas para os anos de 2010 e 2015. Dados auxiliares são obtidos através das pesquisas setoriais do IBGE (2020). Os resultados obtidos indicam o aumento (também em termos relativos) das atividades não-produtivas na economia, o que pode implicar em dificuldades de crescimento futuro.

O presente estudo está estruturado em quatro partes adicionais além desta introdução. Na seção 2 apresenta-se uma revisão de literatura, com tópicos dedicados às definições de "atividades não-produtivas" e "trabalho não-produtivo" sob a ótica do valor. A seção 3 introduz a metodologia desenvolvida por Shaikh e Tonak (1994), denominada clássico-marxiana. A seção 4 exibe os resultados. Por fim, a seção 5 apresenta as conclusões.

\section{Revisão Teórica e Empírica}

Esta seção apresenta os conceitos de atividade produtiva/não-produtiva e trabalho produtivo/não-produtivo. A subseção 2.1 distingue atividades produtivas e não-produtivas na tradição da economia política clássica-marxiana. A seção 2.2 apresenta o conceito de trabalho não-produtivo e suas implicações teóricas. A seção 2.3 apresenta uma breve revisão da literatura empírica sobre o tema.

\subsection{Atividades Produtivas e Não-Produtivas}

A corrente clássico-marxiana propõe uma alternativa à contabilidade social convencional, resgatando conceitos originados nos autores da economia política clássica para a construção de novos indicadores macroeconômicos. Inserido nessa tradição, o presente artigo adapta a metodologia proposta por Shaikh \& Tonak (1994) para a economia brasileira.

A obra de Smith (1983[1776]) inaugura uma hipótese central para as investigações feitas sob esta metodologia: A lógica expansionista de acumulação produtiva, inerente ao modo de produção capitalista, proporciona uma tendência de crescimento de atividades não-produtivas, o que reduz a capacidade produtiva potencial e prejudica o desempenho da economia no longo prazo. Ainda assim, é em Marx (2013[1867]) que as implicações da lógica de expansão capitalista se explicitam.

\footnotetext{
${ }^{2}$ Pode-se destacar também estudos como Mage (1963), Shaikh (1978), Cockshott e Cotrell (1995), Mohun (1998), López e Insua (2019), dentre outros.
} 
Sob a ótica marxiana, uma atividade econômica produtiva é aquela dedicada à produção de mercadorias que, por definição, possuem valor de uso, valor de troca, e maisvalor, fonte do lucro capitalista. As atividades não-produtivas, por sua vez, são responsáveis pela circulação ou redistribuição de valores pré-existentes, sem a adição de um valor excedente para o agregado da economia. Estas atividades não resultam, portanto, na produção de novas mercadorias, mas sim na manutenção de elementos necessários à reprodução social (DUTT, 1992; SHAIKH e TONAK, 1994).

A definição marxiana não se refere a atividades "necessárias" e "desnecessárias" para a economia, tampouco pode ser relacionada a uma falsa dicotomia entre "indústria" e "serviços", ou entre as esferas pública e privada. O caráter produtivo ou não-produtivo de uma atividade é definido de acordo com sua relação com a produção de mais-valor, e posição no circuito do capital (SAVRAN e TONAK, 1999; TREGENNA, 2011).

No âmbito do setor público, as empresas estatais que se dedicam à produção de mercadorias, revendidas no mercado para a realização do lucro, são classificadas como parte da esfera produtiva da economia. Por outro lado, as competências da administração pública e os serviços prestados à população não têm como objetivo a produção de maisvalor, e, portanto, compõem a esfera não-produtiva. ${ }^{3}$

$\mathrm{O}$ setor privado também engloba atividades produtivas e não produtivas na definição clássico-marxiana. Convém destacar que esta definição não é condicionada à produção de um bem físico, tangível. ${ }^{4}$ Por outro lado, algumas atividades do setor privado não possuem a capacidade de adicionar um valor excedente para a economia, e seu lucro advém da recirculação de valores da esfera produtiva (SHAIKH; TONAK, 1994; TREGENNA, 2011). Esta definição afeta algumas atividades do setor de serviços que ocupam outras posições no circuito do capital produtivo, não tendo participação direta na produção do mais-valor. Sobre a noção de atividade produtiva em Marx, explica Tregenna (2011, p. 286, tradução própria) $)^{5}$ :

\footnotetext{
${ }^{3}$ Os serviços públicos de educação e saúde são classificados como parte da esfera não-produtiva. No âmbito do setor privado, estas atividades produzem valores de uso (aulas, consultas médicas) comercializados para a realização do mais-valor originado do trabalho não pago de professores e profissionais de saúde. Entretanto o caráter produtivo destes setores é restrito à sua versão mercantil, não existindo produção de mercadorias na oferta pública destes serviços (SAVRAN e TONAK, 1999, p. 138-140).

${ }^{4}$ Marx (2013[1867]) não faz distinção entre o capital aplicado em uma "fábrica de ensino" (escola) ou em uma fábrica de salsichas, na medida em que ambas produzem mercadorias e por consequência, mais valor.

5 "In terms of the circuit of productive capital (M-C...P....'-M'), value is expanded in the commodity production process $P$, specifically through the contribution of labour power [...] The first axis along which activities can be classified is therefore between those in which surplus-value is generated (i.e. in which value increases), which is the stage $P$, and activities in the other parts of the circuit of capital, $\mathrm{M}-\mathrm{C}$ and $\mathrm{C}^{\prime}-\mathrm{M}^{\prime}$. Any further distinctions between different types of surplus-value-producing processes, or different types of non-surplusvalue-producing processes, are secondary to this primary distinction between $P$ and activities in the rest of the circuit of capital".
} 
em termos do circuito do capital $\left(D-M \ldots P \ldots M^{\prime}-D^{\prime}\right)$, o valor é expandido no processo de produção de mercadorias $P$, especificamente através da contribuição da força de trabalho [...] O primeiro eixo ao longo do qual as atividades podem ser classificadas está, portanto, entre aquelas em que a mais-valia é gerada (ou seja, em que o valor aumenta), que é o estágio $P$, e as atividades nas demais partes do circuito do capital, $D-M$ e $M^{\prime}-D^{\prime}$. Quaisquer outras distinções entre diferentes tipos de processos de produção de mais-valor, ou diferentes tipos de processos de não produção de mais-valor, são secundárias a esta distinção primária entre $P$ e atividades no resto do circuito do capital.

Seguindo a tradição marxista, é possível enquadrar neste critério as atividades jurídicas, administrativas, financeiras, imobiliárias e de segurança privada (SHAIKH; TONAK, 1994; SAVRAN; TONAK, 1999; PINTO, 2007; ROTTA, 2018). A delimitação entre as esferas produtiva e não-produtiva da economia é central para a metodologia de contabilidade social proposta por Shaikh e Tonak (1994). Os autores utilizam a categoria de consumo social para classificar os setores não-produtivos, no que representa um retorno à concepção abrangente de consumo da economia política clássica. A consolidação da concepção neoclássica de produção nos modelos de contabilidade social, por outro lado, representa:

[...] um recuo em relação à abordagem de "consumo abrangente" dos clássicos (que trata muitas atividades como formas de consumo social, e não produção), em favor da definição de "consumo restrito" dos neoclássicos (que restringem a definição de consumo social apenas ao consumo pessoal). (SHAIKH; TONAK, 1994, p. 3).

Autores que reivindicam esta delimitação têm investigado a hipótese de que as atividades não-produtivas têm elevado sua participação na economia global. Considerando que a acumulação capitalista depende do constante reinvestimento do mais-valor, a crescente tendência de transferência de recursos para a fora da esfera de produção tende a diminuir a acumulação potencial, exercendo efeitos negativos sobre o crescimento e a lucratividade da economia (MOSELEY, 1983; SHAIKH e TONAK, 1994; MOHUN, 2014).

Em estudo para a economia estadunidense, Paitaridis e Tsoulfidis (2012) explicam este fenômeno a partir de três fatores: o aumento dos gastos com encargos administrativos e publicidade, provocado pelo acirramento da competição capitalista; maiores investimentos públicos em bem-estar social; e o maior volume de gastos militares no contexto da guerra fria.

Autores desta tradição têm investigado um fenômeno complementar à expansão dos setores não-produtivos: o crescimento da mão de obra empregada de maneira nãoprodutiva. A seção seguinte delimita o conceito de trabalho produtivo/não-produtivo sob a ótica da criação de valor. 


\subsection{Trabalho Produtivo e Não-Produtivo}

O trabalho produtivo é uma formação social característica do modo de produção capitalista. Ao definir esta categoria, Marx (1980[1905], p. 133) utiliza o exemplo de um camponês que com sua força de trabalho reproduz somente as condições necessárias para sua própria subsistência. A mão de obra do camponês é produtiva em termos absolutos, mas não é produtiva sob a ótica do capital. A produtividade do trabalho assume, sob o capitalismo, um caráter relativo, sendo necessário materializar nas mercadorias um valor maior do que necessário para a reposição da força de trabalho. No primeiro volume d' $O$ Capital, o autor enuncia:

Por outro lado, o conceito de trabalho produtivo se estreita. A produção capitalista não é apenas produção de mercadoria, mas essencialmente produção de mais-valor. O trabalhador produz não para si, mas para o capital. Não basta, por isso, que ele produza em geral. Ele tem de produzir mais-valor. Só é produtivo o trabalhador que produz mais-valor para o capitalista ou serve à autovalorização do capital. [...]a economia política clássica sempre fez da produção de mais-valor a característica decisiva do trabalhador produtivo. (MARX, 2013[1867], p. 578).

Esta definição é similar ao entendimento de Adam Smith em A Riqueza das Nações. Em posição crítica aos gastos do Estado britânico com as corporações militares e funcionários da realeza, o autor adverte para os efeitos nocivos da elevação do trabalho não-produtivo, conforme segue:

\footnotetext{
Existe um tipo de trabalho que acrescenta algo ao valor do objeto sobre o qual é aplicado; e existe outro tipo, que não tem tal efeito. O primeiro, pelo fato de produzir um valor, pode ser denominado produtivo; o segundo, trabalho improdutivo. Assim, o trabalho de um manufator geralmente acrescenta algo ao valor dos materiais com que trabalha: o de sua própria manutenção e o do lucro de seu patrão. Ao contrário, o trabalho de um criado doméstico não acrescenta valor algum a nada. Embora o manufator tenha seus salários adiantados pelo seu patrão, na realidade ele não custa nenhuma despesa ao patrão, já que o valor dos salários geralmente é reposto juntamente com um lucro, na forma de um maior valor do objeto no qual seu trabalho é aplicado. Ao contrário, a despesa de manutenção de um criado doméstico nunca é reposta. Uma pessoa enriquece empregando muitos operários, e empobrece mantendo muitos criados domésticos. (SMITH, 1983[1776], p. 333).
}

Conforme explica Marx (1980[1905], p. 140) em revisão crítica da concepção de trabalho produtivo em teóricos predecessores, a posição de Smith não é constante ao longo de sua obra. Em outros escritos, o autor britânico adota uma concepção estritamente material do trabalho produtivo, condicionando este conceito à produção de um bem físico, tangível, no que Marx (1980[1905], p. 142) considera ser uma lógica fisiocrata expandida à produção industrial.

Em termos marxianos, trabalho produtivo é aquele trocado por capital, dotado da capacidade de fornecer renda ao capitalista, em contraste com o trabalho não-produtivo, trocado por renda (lucro ou salário). Esta definição independe das propriedades da mercadoria produzida. Para Marx, um palhaço ou um professor pode ser um trabalhador 
produtivo desde que exista um capitalista extraindo lucro destas atividades (MARX, 1980[1905], p. 137).

Uma das dificuldades encontradas por estudos empíricos reside na delimitação do trabalho não-produtivo empregado em setores produtivos, sendo recorrente na literatura o uso de variáveis proxy. A definição de trabalho improdutivo empregado pelo capital permite estabelecer duas subcategorias para este tipo de ocupação: o trabalho de circulação e o trabalho de supervisão (MARX, 1980). A primeira se refere às funções correlacionadas com a venda de mercadorias, como publicidade, contabilidade, gerência de estoques, dentre outras. A segunda diz respeito às atribuições de fiscalização e supervisão que têm como objetivo garantir que cada trabalhador dê o máximo de si no processo produtivo.

Tsoulfidis et al. (2019) resgatam uma declaração de Alfred Marshall, que afirma rejeitar a categoria de trabalho não-produtivo devido à grande dificuldade em estimar a parcela não produtiva da mão de obra, sendo mais simples considerar todo trabalho como produtivo. Segundo os autores a rejeição da economia neoclássica a esta definição não se deve a uma suposta inconsistência teórica, e os estudos voltados para esta categoria de análise denotam sua relevância para a análise da economia global.

Os estudos que resgatam a definição clássico-marxiana consideram que a competição capitalista tem estimulado uma crescente alocação de trabalhadores em funções não ligadas à produção. A renda desses funcionários, entretanto, advém do mais-valor criado por trabalhadores produtivos, limitando à autovalorização do capital (MOSELEY, 1983). Desta forma, a literatura contemporânea tem constatado que a expansão das ocupações nãoprodutivas é uma das características do capitalismo contemporâneo.

\subsection{Revisão Empírica}

Os estudos empíricos têm enfatizado a lucratividade e a exploração do trabalho como fatores determinantes da dinâmica de acumulação dos países. Esta abordagem se diferencia da tradição neoclássica, que atribui este papel a elementos como o progresso técnico exógeno, a produtividade total dos fatores e o acúmulo de capital humano (SHAIKH, 2016).

Autores como Shaikh e Tonak (1994), Cronin (2001) e Paitaridis e Tsoulfidis (2012, 2019) realizaram estimativas a partir da delimitação entre as esferas produtiva e nãoprodutiva da economia. Nestes trabalhos, reside a hipótese geral de que a expansão dos setores e empregos não-produtivos implica uma crescente transferência de mais-valor para fora do circuito de autovalorização do capital. Os resultados denotam o potencial explicativo desta metodologia para a análise das economias, bem como as limitações das análises tradicionais.

Moseley (1983) relaciona a crise de estagflação norte-americana com o crescimento da parcela não-produtiva da mão de obra. Ao longo do período 1947 e 1977, o total de trabalhadores empregados na produção cresceu $35 \%$, frente a um aumento de $143 \%$ dos trabalhadores não-produtivos. A razão entre as remunerações não-produtivas e 
o capital variável, empenhado na contratação de trabalhadores produtivos, apresenta crescimento de $82 \%{ }^{6}$

Em estudo posterior para o mesmo país, Paitaridis e Tsoulfidis (2012) constatam a contínua expansão da esfera não-produtiva no período 1964-2007. O período neoliberal (a partir dos anos 1980) combinou ganhos de produtividade do trabalho e estagnação dos salários, o que proporcionou forte crescimento da taxa de mais-valor. Apesar da maior massa de mais-valor expropriada, o lucro líquido agregado permaneceu a níveis similares aos precedentes à crise de estagflação. Este resultado é indicativo da expansão das atividades não-produtivas, que se reproduzem a partir do mais-valor criado na esfera produtiva.

Paitaridis e Tsoulfidis (2019) estimam o valor auferido pelos setores nãoprodutivos como proporção do valor adicionado marxiano (MVA), verificando aumento de 27,2\% neste indicador para o período 1964-2016. A participação relativa do trabalho nãoprodutivo apresenta suave tendência ascendente, oscilando em torno de $55 \%$ do total de ocupações no mesmo período. Os salários não-produtivos, por sua vez, apresentaram trajetória de crescimento mais acentuada, representando mais de $70 \%$ do total de remunerações ao final da série.

Rotta (2018) expõe conclusões semelhantes em estudo para a economia americana no período $1947-2011$, onde se destaca o aumento de $220 \%$ no mais-valor transferido dos setores produtivos para a esfera não-produtiva. A guinada neoliberal promove a retomada da trajetória ascendente da taxa de mais-valor, interrompida ao final dos anos 1960, que passa a ocupar o maior patamar da série histórica em 2011 . O crescimento da taxa de maisvalor guarda forte correlação com a participação dos $0.1 \%$ mais ricos na renda norteamericana.

A partir dos anos 1970, as ocupações não-produtivas assumem a predominância do mercado de trabalho. A razão entre as remunerações não-produtivas e o capital variável apresenta trajetória análoga, atingindo $150 \%$ ao final da série. Os resultados permitem afirmar que a retomada da trajetória ascendente da taxa de lucro no período neoliberal está ligada a uma maior exploração de trabalhadores produtivos, em um contexto favorável à expansão de setores não-produtivos (ROTTA, 2018).

Em estudo para a economia chinesa, Qi (2017) acompanha a evolução das atividades não-produtivas no período 1956-2014. A abertura comercial, ao final dos anos 1970, proporciona uma trajetória declinante para a taxa de mais-valor, com maiores transferências de excedente para setores não-produtivos. A taxa de mais-valor se recupera a partir de 1997, atingindo seu patamar mais elevado às vésperas da crise financeira global de 2007-2008. A contínua expansão da esfera não-produtiva no período é apontada como determinante para o declínio da taxa de mais-valor no pós-crise.

\footnotetext{
${ }^{6} \mathrm{O}$ autor demonstra algebricamente que um aumento nesta razão, não acompanhado pela trajetória da taxa de mais-valor, reduz a quantidade de mais-valor disponível para acumulação. Esta tendência se verifica mais fortemente a partir de 1965, sendo decisiva para o cenário de estagflação da década seguinte.
} 
É recorrente na literatura a utilização do referencial clássico-marxiano para a análise dos efeitos de reformas liberalizantes. Destacam-se as investigações de Mariña e Moseley (2000), Cronin (2001) e Rieu e Park (2020), que analisam o comportamento da taxa de mais-valor no México, Nova Zelândia e Coreia do Sul, respectivamente. Estes estudos sugerem que políticas de ataque a direitos trabalhistas e redes de amparo social elevam a taxa de exploração, permitindo a retomada da lucratividade.

No caso mexicano, a taxa de mais-valor dobra no período 1976-1993, mas as crescentes transferências do excedente expropriado para setores não-produtivos retardam a retomada da taxa de lucro, que se mantém declinante até o final dos anos 1980 (MARIÑA; MOSELEY, 2000). Na Nova Zelândia, a agenda reformista proporciona uma trajetória ascendente para a taxa de mais-valor a partir de 1984. Cronin (2001) demonstra que a melhora no desempenho da economia, expressada em indicadores convencionais, reflete, na verdade, a expansão da esfera não-produtiva em um contexto de declínio no emprego e valor adicionado dos setores produtivos.

Em um balanço crítico da economia sul-coreana, partindo da crise asiática dos anos 1990, Rieu e Park (2020) constatam que a expansão das atividades não-produtivas no país foi acompanhada de uma maior exploração do trabalho não-produtivo. Este fato se denota pela queda na participação destes trabalhadores no total de salários da economia. Trata-se de mais um caso onde a precarização do trabalho cria as condições para a retomada da lucratividade capitalista.

Existem algumas aplicações da metodologia de Shaikh e Tonak (1994) para a economia brasileira. Os trabalhos de Pinto (2007) e Araújo (2013) compreendem o período da abertura econômica dos anos 1990 até o primeiro governo Lula. Os autores identificam a perda contínua de participação relativa das atividades e ocupações produtivas no país, e a pauperização relativa do trabalhador dada a trajetória ascendente da taxa de exploração.

Freitas (2020) encontra resultados distintos para o mercado de trabalho no governo Lula I, onde se verifica a retomada do protagonismo do emprego produtivo no Brasil. Esta tendência, assim como a alta da taxa de mais-valor, é revertida após a crise de 2008, fazendo com que a desaceleração da economia brasileira fosse acompanhada por uma expansão da esfera não-produtiva, conforme previsto na literatura. Em 2016, último ano da série, há retomada do crescimento da taxa de exploração, indicativo da agenda reformista adotada para o enfrentamento da crise.

Os estudos dedicados à economia brasileira enfrentam problemas relacionados às limitações das bases de dados disponíveis. É recorrente a construção de séries históricas a partir de dados auferidos sob metodologias distintas de contabilidade nacional, provocando distorções nos resultados. O presente artigo preenche uma lacuna na literatura, realizando estimativas a partir das matrizes insumo-produto 2010 e 2015 , atualmente as únicas disponíveis na versão mais recente do SNA, datada de 2008, assegurando coerência metodológica dos dados primários utilizados. 


\section{Metodologia}

Nesta seção são apresentadas as adaptações necessárias para a aplicação da metodologia de Shaikh e Tonak (1994) para o caso brasileiro. O objetivo é efetuar a separação entre as atividades produtivas e não-produtivas, permitindo assim a estimativa das principais categorias marxianas de análise, para os anos de 2010 e 2015. Para os anos de referência, serão utilizadas as matrizes-insumo produto disponibilizadas pelo Instituto Brasileiro de Geografia e Estatística (IBGE), além de pesquisas setoriais complementares para as estimativas do trabalho produtivo/não-produtivo e do capital variável.

Neste trabalho, utilizando o grau de desagregação em 67 atividades, são considerados não-produtivos os seguintes setores: Comércio; Intermediação financeira, seguros, previdência complementar e outros serviços; Imobiliário; Aluguéis não imobiliários; Jurídico, contábil e consultoria; Segurança privada; Educação pública; Saúde pública; Administração pública; e Outras atividades administrativas. Uma vez delimitadas as esferas produtiva e não-produtiva da economia, é possível operacionalizar a metodologia a partir do cálculo do valor adicionado marxiano

O valor adicionado marxiano (MVA) é calculado como a diferença entre o valor total $(T V *)$, calculado sob a ótica marxiana, e o capital constante $\left(\mathrm{C}^{*}\right)$. O valor total, sob a ótica marxiana, $(T V *)$ é composto pelo valor bruto da produção dos setores considerados produtivos (VBPp). ${ }^{7}$ Por sua vez, o capital constante $(C *)$ é estimado a partir do somatório entre o consumo intermediário dos setores produtivos $\left(M^{\prime} p\right)$ e a depreciação $(D p)$. As equações (1), (2) e (3) expressam essas relações

$$
\begin{gathered}
M V A=T V *-C * \\
T V *=V B P p \\
C *=M^{\prime} p+D p
\end{gathered}
$$

(1), em que:

A etapa seguinte envolve as estimativas para o trabalho produtivo e remunerações produtivas. As pesquisas setoriais do IBGE voltadas para o segundo setor, tais como a Pesquisa Industrial Anual (PIA) e Pesquisa Anual da Indústria de Construção (PAIC), fornecem dados de ocupação e salários desagregados entre profissionais vinculados e não vinculados à produção. Esta delimitação é utilizada como uma aproximação das categorias marxianas de trabalho produtivo e não-produtivo.

As pesquisas para os setores de agropecuária e serviços não dispõem desta mesma desagregação. Dada esta limitação, considera-se a participação relativa das ocupações

7 O presente artigo segue a proposição de Lopez e Insua (2019) que divergem de Shaik e Tonak (1994), e consideram o setor comercial como não produtivo. Segundo Lopes e Insua $(2019$, p. 81) "a atividade comercial que emprega trabalho assalariado é parte da circulação e da realização do valor gerado no setor produtivo. O capital comercial se apropria de parte do valor gerado na esfera produtiva por meio das margens de comércio". 
ligadas à produção no setor industrial para a totalidade da esfera produtiva, dada por $\Omega$, pode ser aplicada aos demais setores produtivos da economia. Desta forma, considerandose de forma genérica a existência de $\mathrm{n}$ setores produtivos em setores não-produtivos na economia, é possível estimar a participação relativa do trabalho produtivo na economia $\left(\frac{L_{p}^{\prime}}{L_{T}}\right)$, conforme a equação (5), onde $L_{p i}$ é o total de trabalhadores do setor produtivo $i$ e $L_{I j}$ é o total de trabalhadores do setor não-produtivo $j$.

$$
\frac{L_{p}^{\prime}}{L_{T}}=\frac{\Omega \sum_{i=1}^{n} L_{p i}}{\sum_{i=1}^{n} L_{p i}+\sum_{j=1}^{m} L_{I j}}
$$

O trabalho total $L_{T}$ é determinado pelo somatório do trabalho total presente no conjunto dos setores da economia. Por sua vez, $L_{p}^{\prime}$ representa o número de trabalhadores efetivamente produtivos da economia, deduzida a parcela não-produtiva das ocupações do setor produtivo. $\mathrm{O}$ cálculo da participação relativa das remunerações produtivas no total de salários $\left(\frac{V}{w_{t}}\right)$ é estimado, de forma análoga, conforme a equação (6):

$$
\frac{V}{w_{t}}=\frac{\alpha \sum_{i=1}^{n} W_{p i}}{\sum_{i=1}^{n} \quad W_{p i}+\sum_{j=1}^{m} W_{I j}}
$$

Na equação (6), $W_{p i}$ e $W_{I j}$ representam, respectivamente, as remunerações do total de trabalhadores do setor produtivo $i$ e do setor não-produtivo $j$ da economia. Utilizandose os dados disponíveis para o setor industrial, obtém-se a razão entre os salários dos trabalhadores produtivos e o total de trabalhadores do setor industrial, $\alpha$. A razão $\alpha$ é aplicada ao total de remunerações pagas ao total de trabalhadores dos $n$ setores produtivos, e este resultado é dividido pelo total de remunerações pagas ao total de trabalhadores da economia. Cabe ressaltar que é possível assim obter uma estimativa para as remunerações efetivamente ligadas à produção nos setores produtivos, o que equivale à categoria marxiana de capital variável $(V)$. Este indicador será utilizado na parte final do procedimento empírico desenvolvido por Shaikh e Tonak (1994), voltada para o cálculo das variáveis massa de mais-valor (7), taxa de mais-valor, ou taxa de exploração (8) e taxa de lucro (9), conforme segue:

$$
\begin{gathered}
S=M V A-V \\
S *=S / V \\
r *=S /(C *+V)
\end{gathered}
$$


Os procedimentos matemáticos descritos nesta seção são base para a operacionalização da metodologia clássico-marxiana de contabilidade social. Esta abordagem representa uma alternativa aos indicadores econômicos convencionais, utilizando categorias-chave da economia política. As variáveis estimadas podem ser utilizadas para a construção de outros indicadores complementares, tais como a composição orgânica do capital $(C * / V)$ e a produtividade do trabalho em termos marxianos $(M V A / L p)$, dentre outras análises descritas por Shaikh e Tonak (1994).

\section{Metodologia}

Esta seção apresenta e discute os resultados da aplicação do modelo clássicomarxiano para o Brasil. Os valores apresentados encontram-se a preços constantes de 2010. A Tabela 1 apresenta as variáveis macroeconômicas convencionais para os anos 2010 e 2015. Nela, observa-se a expansão da economia no período supracitado. O valor bruto da produção (VBP) apresentou crescimento de 6,36\% entre os dois anos analisados.

Tabela 1 - Agregados macroeconômicos convencionais para a economia brasileira (2010 e 2015) (em R \$ milhões, preços de 2010)

\begin{tabular}{llll}
\hline \hline \multirow{2}{*}{ Resultados MIP } & \multicolumn{3}{l}{ Ano de referência } \\
& 2010 & 2015 & $\Delta \%$ \\
\hline CI (Total) & 2.713 .231 & 2.808 .683 & 3,52 \\
Remunerações & 1.618 .190 & 1.833 .793 & 13,32 \\
EOB e rendimentos & 1.641 .762 & 1.664 .149 & 1,36 \\
Impostos e Importações & 583.078 & $671.701,3$ & 15,20 \\
Outros impostos e subsídios & 42.888 & $40.319,12$ & $-5,99$ \\
Valor Bruto da Produção (VBP) & 6.599 .149 & 7.018 .645 & 6,36 \\
Demanda Final & 3.885 .918 & 4.209 .963 & 8,34 \\
Valor Adicionado (VA) & 3.302 .840 & 3.538 .261 & 7,13 \\
Razão Lucro-Salário & 0,810096 & 0,7205841 & $-11,05$ \\
Razão Lucro-Capital Investido & 0,323195 & 0,3025696 & $-6,38$ \\
\hline \hline
\end{tabular}

Fonte: IBGE (2016; 2018); Elaboração própria. 
Na Tabela 2 são apresentados os indicadores, com base na metodologia de Shaikh e Tonak (1994), obtidos a partir da distinção entre as esferas produtiva e não-produtiva da economia nacional. $\mathrm{O}$ valor bruto da produção é decomposto entre as esferas produtiva e não-produtiva, em uma etapa preliminar ao cálculo do valor adicionado sob a ótica marxiana.

\section{Tabela 2 - Valor Bruto da Produção dos setores produtivos e não-produtivos do Brasil (2010 e 2015) (em R\$ milhões, preços de 2010)}

\begin{tabular}{llll}
\hline \hline Valor Bruto da Produção & 2010 & 2015 & $\Delta \%$ \\
\hline Setores Produtivos (VBP) & 4.405 .809 & 4.291 .991 & $-2,58$ \\
Setores Não-produtivos (VBP) & 2.193 .340 & 2.726 .655 & 24,32 \\
VBPnp/VBP Total & 0,332367 & 0,388487 & 16,89 \\
CInp/CI Total & 0,218627 & 0,235648 & 7,79 \\
\hline \hline
\end{tabular}

Fonte: IBGE (2016; 2018); Elaboração própria.

Os resultados sinalizam a expansão das atividades não-produtivas entre 2010 e 2015. Ao proceder-se a desagregação do VBP entre setores produtivos e não-produtivos observa-se que o VBP dos setores produtivos apresentou queda de 2,58\%. Em contraste, o VBP dos setores não-produtivos cresceu $24,32 \%$, elevando sua participação relativa no VBP total da economia.

Os resultados obtidos indicam que a queda no VBP dos setores produtivos condiciona o resultado também declinante para o valor adicionado marxiano (MVA), apresentado na Tabela 3. Conforme a equação (7), o MVA é um dos determinantes do mais-valor produzido na economia, de acordo com a metodologia de Shaikh e Tonak (1994). O recuo de 6,76\% neste indicador reflete a desaceleração sofrida pela produção nacional no período.

Tabela 3 - Valor adicionado marxiano (2010 e 2015) (em R \$ milhões, preços de 2010)

\begin{tabular}{l|l|l|l}
\hline \hline Composição do Valor Adicionado Marxiano & 2010 & 2015 & \multicolumn{1}{l}{$\Delta$} \\
\hline Fluxo primário de renda: TV* = VBPp & 4.405 .809 & 4.291 .991 & $-2,58$ \\
M'p & 2.120 .046 & 2.146 .823 & 1,26 \\
Depreciação (Máquinas + Estruturas) & $237.041,5$ & $234.958,4$ & $-0,88$ \\
$\mathrm{C}^{\prime}=\mathrm{M} ' \mathrm{p}+\mathrm{D}$ & 2.357 .088 & 2.381 .781 & 1,05 \\
$\mathrm{MVA}=\mathrm{TV}^{*}-\mathrm{C}^{*}$ & 2.048 .721 & 1.910 .209 & $-6,76$ \\
\hline \hline
\end{tabular}

Fonte: IBGE (2016; 2018); IPEA (2020); Elaboração própria. 
De acordo com a Tabela 1, a medida convencional para o valor adicionado (VA) apresenta crescimento de 7,13\% na comparação entre os anos. Este resultado contrasta com as estimativas para o MVA, que sinalizam uma tendência oposta. O MVA captura a queda do nível de atividade econômica no período 2010-2015, sugerindo que parte substancial do crescimento do VA deve-se à expansão de atividades não-produtivas. Isto expõe as possíveis limitações da análise de indicadores convencionais e reforça o potencial explicativo da abordagem clássico-marxiana.

Ademais, é possível estimar a participação do trabalho produtivo total no trabalho total $\left(L^{\prime} p / L t\right)$. Conforme discutido nas seções anteriores, a estimativa se vale das pesquisas setoriais do IBGE, cuja disponibilidade de informações é anual, o que permite a análise. O resultado para o período entre 2010 e 2015 é apresentado no Gráfico 1.

\section{Gráfico 1 - Participação relativa do trabalho produtivo no trabalho total $\left(L^{\prime} p / L t\right)$ na economia brasileira (2010-2015).}

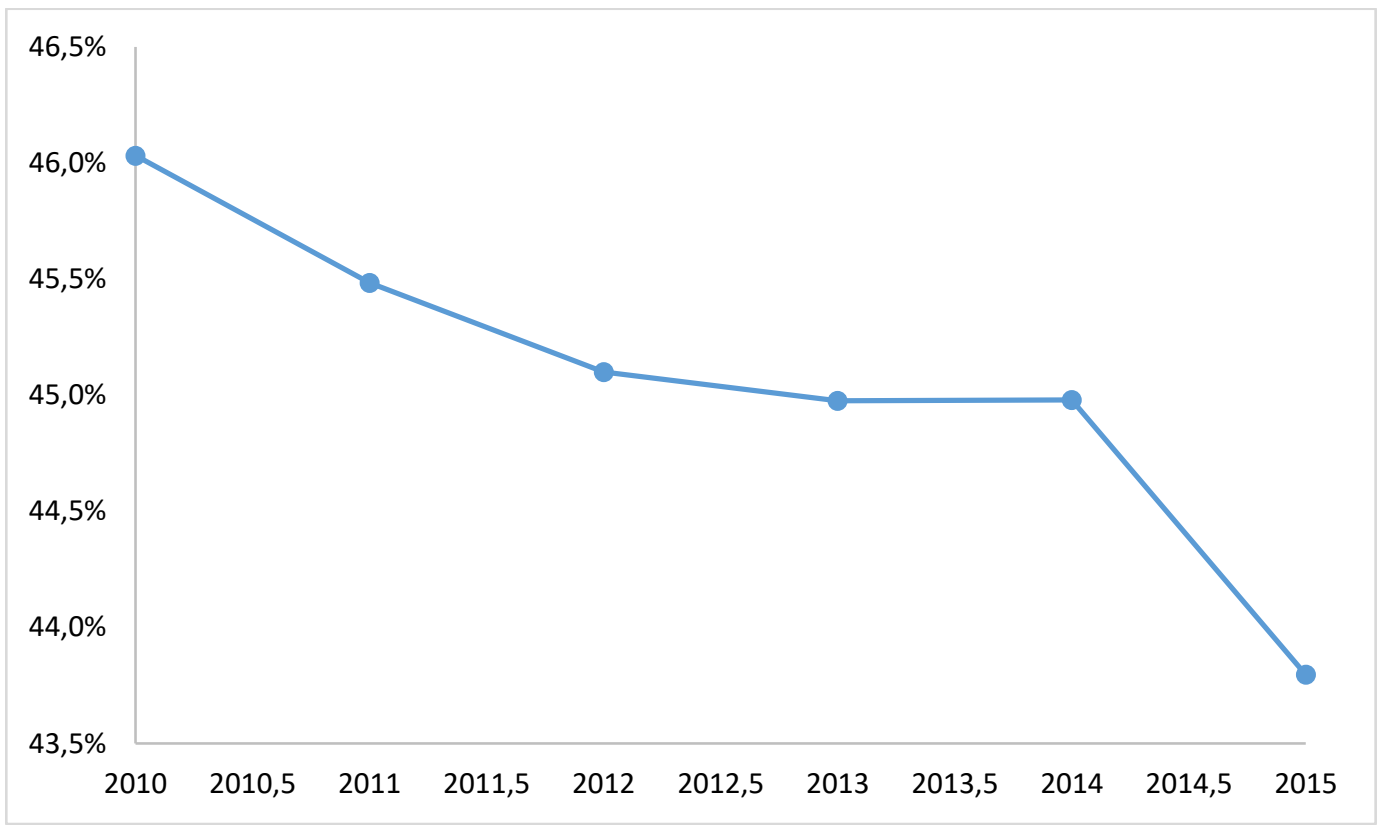

Fonte: Elaboração própria. 
Observa-se uma queda na participação relativa do trabalho produtivo à medida que a economia brasileira perde dinamismo. ${ }^{8}$ A parcela produtiva das ocupações inicia a série no patamar de 46,03\% em 2010, com declínio mais acentuado nos dois anos seguintes. Após relativa estabilidade nos anos de 2013 e 2014, girando em torno de $45 \%$ do total de ocupações, o trabalho produtivo sofre nova queda, alcançando a marca de 43,79\% no ano de 2015.

Por sua vez, a remuneração do trabalho produtivo como proporção do total de salários apresenta comportamento próximo ao observado na proporção entre trabalho produtivo e trabalho total. O Gráfico 2 apresenta a trajetória da participação relativa das remunerações produtivas - equivalentes ao capital variável - no total de salários da economia brasileira, estimada a partir da equação (6).

\section{Gráfico 2 - Remunerações dos trabalhadores produtivos como proporção do total de remunerações $(V / W t)$ no mercado de trabalho brasileiro (2010-2015).}

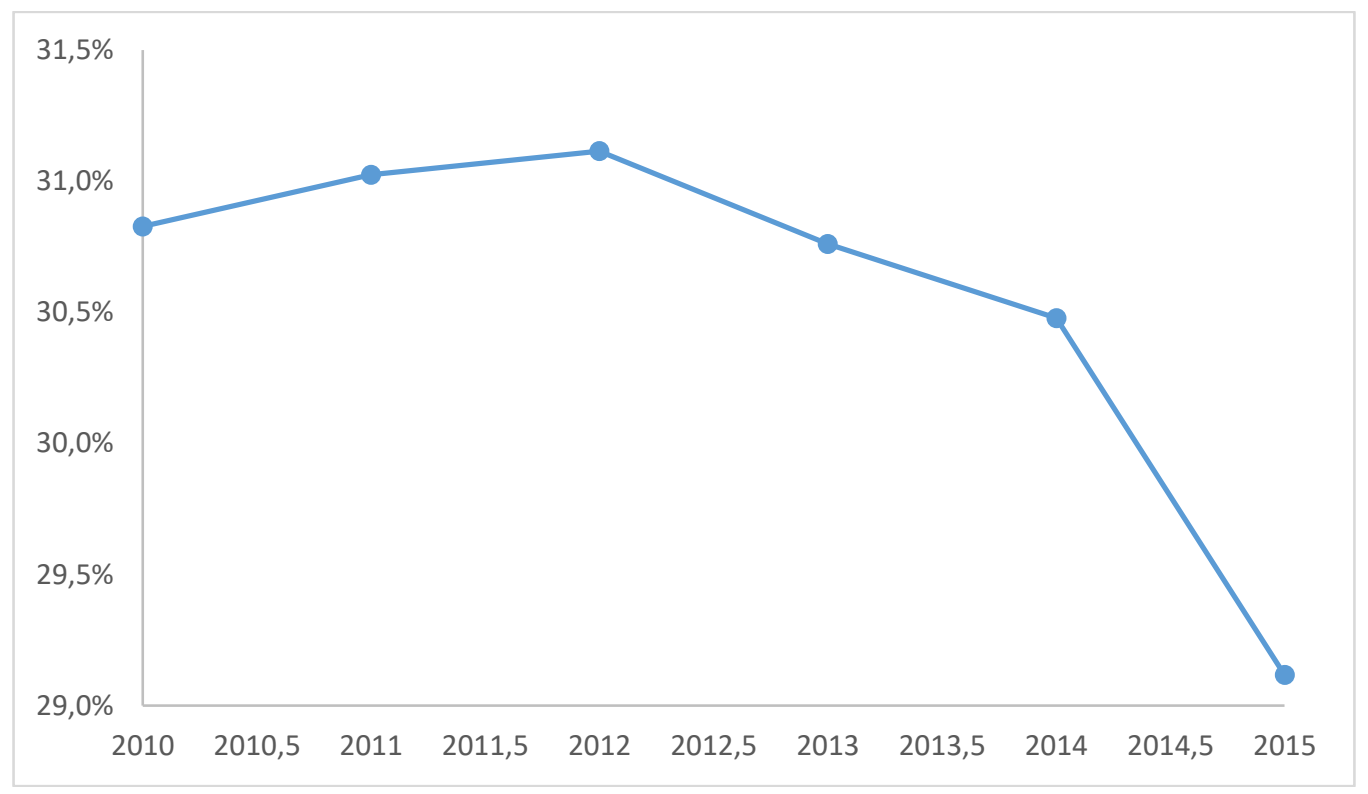

Fonte: Elaboração própria.

\footnotetext{
${ }^{8}$ Durante o primeiro governo Dilma (2011-2014), o PIB real apresentou um crescimento médio anual de 2,34\%. O desempenho representa uma desaceleração em relação ao período Lula, que obteve média de $4,07 \%$ no período 2003-2010 (IBGE, 2020).
} 
A participação relativa das remunerações produtivas cresce até 2012, atingindo a marca de $31,11 \%$ do total de salários da economia. Nos três anos seguintes, a trajetória ascendente se reverte, com declínio de 6,42\% neste indicador, que atinge o patamar de $29,12 \%$ no ano de 2015. A análise do mercado de trabalho reforça a hipótese de que a desaceleração, e subsequente crise, vivenciada pela economia brasileira na segunda década do século XXI, foram acompanhadas por uma expansão da esfera não-produtiva da economia. De acordo com a tradição clássico-marxiana, esta tendência implica maiores transferências de mais-valor para fora do processo de acumulação produtiva, o que implica em menor volume de investimentos produtivos e resulta em uma menor taxa de crescimento do estoque de capital e, assim, em uma menor taxa de crescimento econômico.

Trabalhos recentes apresentam análises que permitem uma melhor contextualização dos resultados obtidos. De acordo com Singer (2012; 2018), a expansão do mercado de trabalho promovida pelas gestões do Partido dos Trabalhadores (PT) ocorre em função de ocupações de baixa remuneração, que representaram mais de $90 \%$ dos novos empregos criados. Loureiro (2019; 2020) associa estes novos postos de trabalhos a serviços de baixa remuneração e produtividade, o que, somado a outras características da economia brasileira do período, tais como a hipertrofia do setor produtor de commodities e a queda relativa da participação da indústria, tende corroborar a ideia da tendência de uma regressão da estrutura produtiva do país.

Loureiro $(2019 ; 2020)$ parte do entendimento de que a especialização em setores pouco produtivos não gerou o dinamismo necessário para sustentar a trajetória de crescimento da economia. A partir da metodologia proposta por Shaikh e Tonak (1994), é possível concluir que o ciclo de crescimento cumulativo que se esgota entre 2010 e 2015 teve como uma de suas características a expansão da esfera não-produtiva em termos de produção, mão de obra e salários. A Tabela 4 permite avaliar os efeitos desta tendência sobre a produção de mais-valor e lucratividade do capital, conforme segue:

Tabela 4 - Capital variável, mais-valor e taxas de exploração e lucro (2010 e 2015) (em R\$ milhões, preços de 2010)

\begin{tabular}{llll}
\hline \hline Categorias marxianas & 2010 & 2015 & \multicolumn{1}{c}{$\Delta \%$} \\
\hline Capital Variável & $498.841,4$ & 533.951 & 7,04 \\
Massa de mais-valor & 1.549 .880 & 1.376 .258 & $-11,20$ \\
Taxa de mais-valor & 3,10696 & 2,577499 & $-17,04$ \\
Taxa de lucro & 0,542689 & 0,472011 & $-13,02$ \\
Composição orgânica do capital & 4,725124 & 4,460674 & $-5,60$ \\
Produtividade do trabalho & 0,045361 & 0,04278 & $-5,69$ \\
\hline \hline
\end{tabular}

Fonte: IBGE (2016; 2018); Elaboração própria. 
Os resultados apontam que a massa de mais-valor $(\mathrm{S})$ produzida pela economia brasileira apresenta queda de 11,20\% entre 2010 e 2015 . Este resultado reflete tanto a queda no valor adicionado sob a ótica marxiana (MVA), quanto o aumento em termos absolutos do capital variável, conforme indicado na equação (7). O aumento do capital variável (V) é impulsionado pelos primeiros anos do período de análise, e apresenta crescimento anual superior a $10 \%$ entre 2010 e 2012. Entre 2014 e 2015, a expansão deste indicador se encontra estagnada, com crescimento anual inferior a $1 \%$.

A taxa de mais valor, ou taxa de exploração, é estimada a partir da razão entre a massa de mais-valor e o valor investido na contratação de trabalhadores produtivos, denominado capital variável. O declínio de 17,04\% neste indicador é superior ao recuo de $11,05 \%$ verificado em sua contrapartida ortodoxa, a razão lucro-salário, conforme Tabela 1. Este resultado é compatível com a tendência mapeada em Freitas (2020), que identifica o decrescimento da taxa de exploração ao longo de todo o governo Dilma. O autor verifica a retomada de uma trajetória ascendente para esta variável em 2016, reflexo da agenda liberal-reformista adotada.

$\mathrm{Na}$ tradição da economia política, a lucratividade representa o principal determinante do investimento e da acumulação produtiva em uma economia capitalista. $\mathrm{Na}$ comparação entre os anos de referência, a taxa de lucro ( $\mathrm{r}^{*}$ ) apresenta queda de $-13,02 \%$, refletindo a piora no desempenho macroeconômico do país, e a reversão do ciclo de expansão que permitiu conciliar ganhos simultâneos nos rendimentos do capital e do trabalho. Ao comparar este resultado com a razão lucro-capital investido (Tabela 1), conclui-se que a queda na lucratividade em termos clássico-marxianos é expressa em maior dimensão, com resultado equivalente ao dobro da medida convencional.

A queda da taxa de lucro não pode ser atribuída diretamente ao aumento da composição orgânica do capital, dado o recuo de 5,60\% neste indicador. Desta forma, declínio da lucratividade pode estar relacionado a outros fatores como a compressão de lucros (profit-squeeze) ou a desproporcionalidade setorial entre as esferas produtiva e nãoprodutiva da economia (WEISSKOPF, 1979; SHAIKH; TONAK, 1994). É relevante constatar ainda que, em que pesa as diferentes metodologias adotadas, os resultados obtidos aqui, especialmente associados a queda da taxa de lucro, são consistentes com os obtidos em Marquetti et. al. (2020) e Rutginsky e Martins (2021).

Constata-se ainda que a produtividade do trabalho em termos marxianos apresenta queda de 5,69\% no período analisado. Desta forma, é plausível assumir que a expansão da esfera não-produtiva induziu queda da produtividade do trabalho e assim impactou o crescimento econômico. Esta constatação tende a corroborar a ideia de "mudança estrutural regressiva" presente em Loureiro (2019). Acrescente-se que os resultados obtidos estão em consonância com Freitas (2020), que verifica o declínio da produtividade do trabalho no Brasil a partir de 2013, atribuindo este resultado à expansão do trabalho não-produtivo. A Tabela 5 oferece um panorama geral da esfera não-produtiva: 


\section{Tabela 5 - Evolução da esfera não-produtiva da economia brasileira (2010 e 2015)}

\begin{tabular}{|c|c|c|c|c|}
\hline \multirow{3}{*}{ Setores não-produtivos } & \multicolumn{4}{|c|}{$\Delta \%(2010-2015)$} \\
\hline & & $\mathrm{N}^{\mathrm{o}} \mathrm{de}$ & & \\
\hline & $\begin{array}{l}\text { Consumo } \\
\text { Intermediário }\end{array}$ & $\begin{array}{l}\text { Trabalhadore } \\
\mathrm{S}\end{array}$ & $\begin{array}{l}\text { Massa } \\
\text { Salarial }\end{array}$ & VBP \\
\hline Comércio por atacado e varejo & 20,59 & 5,96 & 24,37 & 63,01 \\
\hline $\begin{array}{l}\text { Intermediação financeira, seguros e previdência } \\
\text { complementar }\end{array}$ & 4,34 & 10,99 & 8,88 & 56,44 \\
\hline Atividades imobiliárias & 49,83 & 21,10 & 18,19 & 139,73 \\
\hline $\begin{array}{l}\text { Atividades jurídicas, contábeis, consultoria e } \\
\text { sedes de empresas }\end{array}$ & 15,49 & 13,67 & 16,65 & $-61,91$ \\
\hline $\begin{array}{l}\text { Aluguéis não-imobiliários e gestão de ativos de } \\
\text { propriedade intelectual }\end{array}$ & 17,13 & 14,36 & 25,08 & 13,89 \\
\hline $\begin{array}{l}\text { Outras atividades administrativas e serviços } \\
\text { complementares }\end{array}$ & 5,14 & 17,43 & 25,61 & 35,84 \\
\hline Atividades de vigilância, segurança e investigação & 24,57 & 20,19 & 33,30 & $-43,04$ \\
\hline Administração pública, defesa e seguridade social & 0,45 & $-1,26$ & $-0,51$ & 10,93 \\
\hline Educação pública & 7,41 & 9,66 & 39,63 & 9,25 \\
\hline Saúde pública & 9,68 & 21,80 & 21,86 & 18,94 \\
\hline Esfera não-produtiva & 0,63 & 8,22 & 16,12 & 24,32 \\
\hline Esfera produtiva & 47,24 & $-1,14$ & 7,04 & $-2,58$ \\
\hline
\end{tabular}

Fonte: IBGE (2016; 2018); Elaboração própria.

A Tabela 5 permite compreender como a recessão de 2015 atingiu de forma distinta os setores produtivos e não-produtivos. Analisando os dados até 2014, ano que antecede a crise, verifica-se o crescimento de 5,04\% no número de trabalhadores produtivos, e de $9,59 \%$ para os trabalhadores não-produtivos em relação ao início do recorte temporal. Incorporando 2015 na análise, é possível perceber que a esfera produtiva do mercado de trabalho absorve a quase totalidade dos efeitos da recessão, dado o recuo de 1,13\% nos funcionários empregados em relação a 2010.

Dentre as atividades não-produtivas, apenas as ocupações ligadas à administração pública apresentam comportamento similar, indicando uma possível consequência da agenda de reformas adotada pelo governo brasileiro a partir de 2015. Em termos de geração de emprego se destacam os setores imobiliário, segurança privada e saúde pública, com variação positiva superior a $20 \%$. No quesito valor bruto da produção (VBP), o setor imobiliário novamente se destaca, com aumento de $139,72 \%$ na comparação entre os anos. Os setores comercial e financeiro também apresentam elevado crescimento neste indicador, com variações de $63 \%$ e $56,45 \%$, respectivamente.

Em linhas gerais, a presente discussão indica que a abordagem clássica-marxiana da contabilidade social permite um olhar distinto, e em certa maneira mais profundo sobre 
a articulação entre crescimento econômico, investimento e acumulação de capital. Os resultados obtidos aqui são consistentes com um crescente conjunto de estudos que lançam luz sobre a "década inclusiva", ressaltando os limites do processo, bem como identificam o conflito distributivo como um dos determinantes fundamentais da ruptura com o padrão de crescimento econômico marcado por distribuição de renda e inclusão social.

\section{Conclusão}

O presente estudo objetivou analisar a trajetória recente da economia brasileira através da construção de categorias consistentes com o referencial clássico-marxiano. Os resultados apresentados são compatíveis com as tendências identificadas na literatura. Estudos na tradição clássico-marxiana verificam a contínua expansão das atividades e ocupações não-produtivas em diferentes países. Após a virada neoliberal dos anos 1980, a economia global assume um padrão de baixo crescimento associado a uma mudança estrutural direcionada a setores não-produtivos.

De acordo com a teoria marxiana, as atividades e ocupações não-produtivas dependem da recirculação do mais-valor criado na produção, reduzindo o potencial de acumulação produtiva. Os resultados denotam a relevância destas categorias para a análise da desaceleração do ciclo de crescimento da economia brasileira no século XXI. Na comparação entre 2010 e 2015, a esfera não-produtiva aumentou sua participação relativa em termos de produção, empregos e remunerações. Como consequência, uma menor quantidade de riqueza foi gerada na economia, fato que se denota pela redução de $6,76 \%$ no valor adicionado marxiano (MVA).

A maior predominância de atividades não ligadas à exploração do trabalho produtivo é determinante para a diminuição de $11,20 \%$ na massa de mais-valor. Frente a um aumento nos gastos com capital variável, este resultado proporciona uma redução de $17,04 \%$ na taxa de exploração. Na comparação entre os anos de referência, se verifica a queda da taxa de lucro $(13,02 \%)$. Os resultados obtidos indicam que a trajetória da economia brasileira no período entre 2010 e 2015 é consistente com o arcabouço teórico clássico-marxiano. Explicitando o papel das atividades não-produtivas, a estimação de indicadores clássicos-marxianos permite uma maior compreensão do processo de estagnação e crise experimentado pelo país. Além disso, o referencial adotado explicita a queda da taxa de lucro no período e fornece evidência empírica para a hipótese mudança estrutural regressiva da economia brasileira.

Futuros estudos deverão dirigir-se a buscar ampliar o escopo temporal de análise, bem como buscar distintas estratégias de desagregação setorial a fím de aprimorar os resultados aqui apresentados. O uso de novas bases de dados e o contraste com outras experiências nacionais é relevante para o avanço da agenda desta agenda de pesquisa. 


\section{Referências}

COCKSHOTT, Paul; COTTRELL, Allin; MICHAELSON, Greg. Testing Marx: some new results from UK data. Capital \& Class, v. 19, n. 1, p. 103-130, 1995. Disponível: https://journals.sagepub.com/doi/abs/10.1177/030981689505500105.

CRONIN, Bruce. Productive and Unproductive Capital: A mapping of the New Zealand system of national accounts to classical economic categories, 1972-95. Review of Political Economy, v. 13, n. 3, p. 309-327, 2001. Disponível em: https://www.tandfonline.com/doi/abs/10.1080/09538250120055168.

DUTT, Amitava Krishna. 'Unproductive'sectors and economic growth: A theoretical analysis. Review of Political Economy, v. 4, n. 2, p. 178-202, 1992. Disponível em: https://www.tandfonline.com/doi/abs/10.1080/09538259200000015.

FREITAS, Antônio Albano de. The rate of surplus value in Brazil, 1996-2016. 48 Encontro Nacional de Economia - ANPEC. 2020.

HALLAK NETO, João; RAMOS, Roberto Olinto. A economia não observada no Brasil: um estudo baseado na metodologia do sistema de contas nacionais. Revista de Economia Contemporânea, v. 18 n. 1, p.31-55, 2014.

IBGE - INSTITUTO BRASILEIRO DE GEOGRAFIA E ESTATÍSTICA. Matriz de insumo-produto: Brasil, 2010. Rio de Janeiro: IBGE, Coordenação de Contas Nacionais 2016.

. Matriz de insumo-produto: Brasil, 2015. Rio de Janeiro: IBGE, Coordenação de Contas Nacionais 2018.

Pesquisa Industrial Anual - PIA: banco de dados. Sistema IBGE de Recuperação Automática. Disponível em: https://sidra.ibge.gov.br/pesquisa/piaempresa/quadros/brasil/2018.

Sistema IBGE de Recuperação Automática. Disponível em:
https://sidra.ibge.gov.br/pesquisa/pia-empresa/quadros/brasil/2018.

INSTITUTO DE PESQUISA ECONÔMICA APLICADA - Ipeadata. Dados macroeconômicos. Disponível em: http://www.ipeadata. gov.br.

LÓPEZ, Emiliano; INSUA, Facundo Barrera. The Specific Conditions of the Valorization of Capital in a Dependent Nation: The Case of Argentina (2002-2014). Review of Radical Political Economics, v. 51, n. 1, p. 75-94, 2019. Disponível em: https://journals.sagepub.com/doi/full/10.1177/0486613417726541. 
LOUREIRO, Pedro Mendes. The Ebb and Flow of the Pink Tide: reformist development strategies in Brazil and Argentina. 2019. Tese de Doutorado. SOAS University of London. Disponível em: https://eprints.soas.ac.uk/30985/1/4664 Loureiro.pdf.

Social Structure and Distributive Policies Under the PT Governments: A Poverty-Reducing Variety of Neoliberalism. Latin American Perspectives, v. 47, n. 2, p. 65-83, 2020. Disponível em: https://journals.sagepub.com/doi/abs/10.1177/0094582X19881986.

MAGE, Shane Henry. The law of the falling tendency of the rate of profit: Its place in the Marxian theoretical system and relevance to the U. S. economy. Tese de Doutorado. Columbia University. 1963.

MARIÑA, Abelardo; MOSELEY, Fred. The rate of profit in the postwar Mexican economy, 1950-1993. In: BAIMAN, Ron et al. (org.). Political economy and contemporary capitalism: Radical perspectives on economic theory and policy, p. 184192, 2000.

MARQUETTI, A.; HOFF, C.; MIEBACH, A. Profitability and Distribution: The Origin of the Brazilian Economic and Political Crisis. Latin American Perspectives, v. 47 n.1, 2020. Disponível em: https://journals.sagepub.com/doi/full/10.1177/0094582X19887751.

MARTINS, Guilherme Klein; RUGITSKY, Fernando. The Long Expansion and the Profit Squeeze: Output and Profit Cycles in Brazil (1996-2016). Review of Radical Political Economy. Disponível em: https://journals.sagepub.com/doi/abs/10.1177/0486613420982083.

MARX, Karl. (1905). Teorias da mais-valia: História crítica do pensamento econômico (Livro 4 de O Capital). Rio de Janeiro: Civilização Brazileira, 1980.

(1867). O capital: crítica da economia política - Livro I: o processo de produção do capital. São Paulo: Boitempo, 2013.

(1894). O capital: crítica da economia política - Livro III: o processo global da produção capitalista. São Paulo: Boitempo, 2017.

MOHUN, Simon. Unproductive labor in the US economy 1964-2010. Review of Radical Political Economics, v. 46, n. 3, p. 355-379, 2014.

MOSELEY, Fred. Marx's concepts of productive labor and unproductive labor: an application to the postwar US economy. Eastern Economic Journal, v. 9, n. 3, p. 180189, 1983. Disponível em: https://www.jstor.org/stable/40324865. 
PAITARIDIS, Dimitris; TSOULFIDIS, Lefteris. The growth of unproductive activities, the rate of profit, and the phase-change of the US economy. Review of Radical Political Economics, v. 44, n. 2, p. 213-233, 2012. Disponível em: https://journals.sagepub.com/doi/full/10.1177/0486613411423899.

PAITARIDIS, Dimitris; TSOULFIDIS, Lefteris. Capital intensity, unproductive activities and the Great Recession in the US economy. Cambridge Journal of Economics, v. 43, n. 3, p. 623-647, 2019.

PINTO, José Paulo Guedes. A contabilidade social na perspectiva clássica:(capital produtivo e não-produtivo: traçando um mapa do sistema de contas nacionais brasileiro). 2007. Dissertação (Mestrado em Economia) - Faculdade de Ciências Econômicas, Universidade Federal do Rio Grande do Sul, Porto Alegre, 2007. Disponível em: https://lume.ufrgs.br/handle/10183/12587.

QI, Hao et al. Dynamics of the rate of surplus value and the "new normal" of the Chinese economy. Research in Political Economy, v. 32, n. 1, p. 105-129, 2017. Disponível em: https://www.emerald.com/insight/content/doi/10.1108/S0161723020170000032007/full/html.

RIEU, Dong-Min; PARK, Hyun Woong. Unproductive activities and the rate of surplus value at the industry level in Korea, 1995-2015. Journal of Contemporary Asia, v. 50, n. 2, p. 284-307, 2020. Disponível em: https://www.tandfonline.com/doi/full/10.1080/00472336.2019.1651884.

ROTTA, Tomás N. Unproductive accumulation in the USA: a new analytical framework. Cambridge Journal of Economics, v. 42, n. 5, p. 1367-1392, 2018. Disponível em: https://academic.oup.com/cje/article-abstract/42/5/1367/4823061.

SAVRAN, Sungur; TONAK, E. Ahmet. Productive and unproductive labour: an attempt at clarification and classification. Capital \& Class, v. 23, n. 2, p. 113-152, 1999. Disponível em: https://journals.sagepub.com/doi/abs/10.1177/030981689906800107.

SHAIKH, Anwar. National income accounts and Marxian categories. New School for Social Research, 1978.

SHAIKH, Anwar M.; TONAK, E. Ahmet. Measuring the wealth of nations: The political economy of national accounts. New York: Cambridge University Press, 1994.

SINGER, André. Os sentidos do lulismo: reforma gradual e pacto conservador. São Paulo: Companhia das Letras, 2012. 
O lulismo em crise: um quebra-cabeça do período Dilma (2011-2016). São Paulo: Companhia das Letras, 2018.

SMITH, Adam. (1776). A riqueza das nações: investigação sobre sua natureza e suas causas. São Paulo: Abril Cultural, 1983.

TREGENNA, Fiona. What does the 'services sector'mean in Marxian terms? Review of Political Economy, v. 23, n. 2, p. 281-298, 2011. Disponível em: https://www.tandfonline.com/doi/full/10.1080/09538259.2011.561563.

TSOULFIDIS, Lefteris et al. Classical Political Economics and Modern Capitalism: Theories of Value, Competition, Trade and Long Cycles. London: Springer Nature, 2019.

WEISSKOPF, Thomas E. Marxian crisis theory and the rate of profit in the postwar US economy. Cambridge Journal of Economics, v. 3, n. 4, p. 341-378, 1979. Disponível em: https://www.jstor.org/stable/23596415. 